\title{
Investigation of the Battery Degradation Impact on the Energy Management of a Fuel Cell Hybrid Electric Vehicle
}

\author{
Razieh Ghaderi \\ Department of Mechatronics \\ Arak University \\ Arak, 38156-8-8349, Iran \\ r-ghaderi@msc.araku.ac.ir
}

\author{
Mehdi Soleymani \\ Department of Mechatronics \\ Arak University \\ Arak, 38156-8-8349, Iran \\ Centre for Automotive Engineering and Technology \\ School of Aerospace, Transport and Manufacturing (SATM) \\ Cranfield University, Bedfordshire, MK43 OAL \\ Cranfield, UK \\ m.soleymani@cranfield.ac.uk,m-soleymani@araku.ac.ir
}

\author{
Mohsen Kandidayeni \\ Hydrogen Research Institute \\ Department of Electrical Engineering and Computer Science \\ Université du Québec à Trois-Rivières \\ Quebec, G9A 5H7, Canada \\ mohsen.kandi.dayeni@uqtr.ca \\ Loïc Boulon \\ Hydrogen Research Institute \\ Department of Electrical Engineering and Computer Science \\ Canada Research Chair in Energy Sources \\ for the Vehicles of the Future \\ Universite du Quebec a Trois-Rivieres \\ Quebec, G9A 5H7, Canada \\ loic.boulon@uqtr.ca
}

\begin{abstract}
This paper studies the influence of battery degradation over the performance of a fuel cell hybrid electric vehicle (FCHEV). For this purpose, an optimized fuzzy strategy based on the costs of battery and fuel cell degradations as well as fuel consumption and battery recharging is employed. Simulations are done by two driving cycles for three scenarios based on battery state of health (SOH) and validity of feedback signal. Simulation results prove that battery aging has a considerable impact on the total cost of a FCHEV. Moreover, tuning of the EMS parameters according to the battery SOH decreases the defined cost.

Index Terms-Fuel cell hybrid electric vehicle; Energy management system; Optimization; Battery degradation; Fuel consumption
\end{abstract}

\section{INTRODUCTION}

In recent years, the powertrain electrification of the vehicles is transforming the potent position of internal combustion engines in vehicular application [1]. The increasing pressure on global fossil fuels demand and the change in climate patterns owing to air pollution have provoked the development of various green vehicles, which are promising and practical solutions for the upcoming environmental crises [2]. Among the existing solutions, fuel cell hybrid electric vehicles (FCHEVs), which normally utilize the fuel cell (FC) as the main source of power and another power source such as electro-chemical batteries and/or supercapacitors as the secondary one, have attracted a lot of attentions in academic and industrial domains [3]. Proton exchange membrane FC (PEMFC) is typically used in a FCHEV as the main power source due to its suitable features [4]. However, PEMFCs performs well in lowdynamic and cannot accumulate any energy. In this regard, the use of the secondary power source, which is battery in this manuscript, is essential for absorbing the high dynamic components of the requested power, helping the FC stack to meet the requested power, and store the regenerative braking energy [5]. Lithium-ion battery is the most popular technology in hybrid-electric and electric vehicles (EVs) due to proper energy density, low self-discharge rate, and acceptable power density [6]. The various characteristics of the multiple power sources in a FCHEV have made the efficient performance, hydrogen consumption, and the lifetime of the main powertrain components to a great extent dependent on the design of an energy management strategy (EMS) [7-9]. The existing EMSs for FCHEVs fit into two categories of rule based and optimization based [10]. Some works are also based on the combination of both categories, which is optimization of rulebased strategies [11-14]. In [11], Kandi-D et al. designed a fuzzy logic controller (FLC) combined with genetic algorithm (GA). Moreover, Boukhnifer et al. proposed an optimal strategy based on Pontryagins Minimum Principle (PMP) to reduce $\mathrm{H} 2$ consumption in [15]. One of the key issues hindering the development of FCHEVs is the durability of energy sources where the vehicle might experience inferior performance due to the degradation [16]. However, the degradation of the energy sources and their influence on the performance of a FCHEV tend to be ignored while developing an EMS in the literature. In $[17,18]$, the development of an online model 
for the FC stack and its integration into the EMS design has been proposed. Moreover, the importance of designing health-conscious EMSs has been discussed in [19]. However, the impact of the battery degradation, as a key element of the power train system, on the EMS of FCHEVs has not been already considered in literature, according to the best knowledge of the authors. Batteries are prone to calendar and cycling aging, which are normally diagnosed through capacity fade or the internal resistance increase [20-22]. This aging phenomenon affects their state of health ( $\mathrm{SOH})$. As a result, the EMS of the FCHEV may be influenced by the parametric uncertainty arisen from the battery model variations. This paper deals with the analysis of the battery cycling aging impact on the EMS of a FCHEV. In this respect, two optimized fuzzy logic controllers (FLCs) by means of genetic algorithm (GA) are devised for a new battery model and an aged battery model first. Subsequently, the performance of the optimized FLC of the new battery model is tested for the case that the battery has got aged while the parameters of the mathematical model for the battery state of charge (SOC) calculation have not been updated. Finally, the obtained results from different scenarios are compared and discussed. The model used for this purpose is the IEEE VTS Motor Vehicles Challenge 2017 [23]. The rest of this paper is organized as follows. The modeling of the vehicle is described in section II. Description of energy management strategy is given in section III. The results are discussed in section IV, and finally, the conclusion is given in section $\mathrm{V}$.

\section{MODELING}

The studied FC/battery vehicle has been introduced in IEEE VTS Motor Vehicles Challenge 2017 [23]. The propulsion system is composed of a $15 \mathrm{~kW}$ induction machine fed by a voltage source-inverter through a $80 \mathrm{~V}-40 \mathrm{Ah}$ Lithium Iron Phosphate (LiFePO4) battery pack. The FC is a $16 \mathrm{~kW}, 40-$ $60 \mathrm{~V}$, PEMFC system with a maximum current up to $400 \mathrm{~A}$. The architecture of the modeled electric vehicle is presented in Fig. 1.

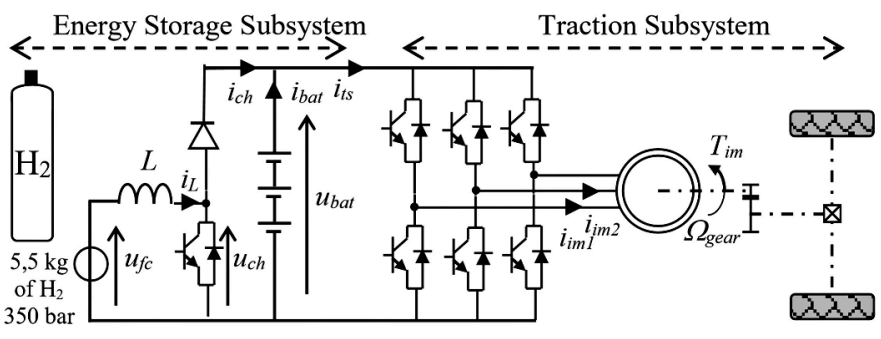

Fig. 1. Fuel cell/battery vehicle architecture [23]

\section{A. Lithium-ion battery}

1RC Thevenin model has been employed for the battery modeling. This model, as illustrated in Fig. 2, Comprises a resistance $\left(R_{s}\right)$ which represents the internal resistance of the battery and a parallel resistance-capacitor which represents the polarization effects. Moreover, $u_{0}$ is the open circuit voltage. Equation (1) describes the governing dynamic equation of the ECN model. Where $i_{b a t}$ is the cell current, $R_{s}$ is the internal resistance, $R_{c}$ is the polarization resistance, $C_{c}$ is the polarization capacity, and $u_{b a t}$ is the cell terminal voltage. The battery SOC is also calculated by (2) using coulomb counting method. Where, $S O C_{\text {init }}$ is the initial SOC of the battery, $i_{\text {bat }}$ is the battery current and $Q_{b a t}$ is the maximum battery capacity.

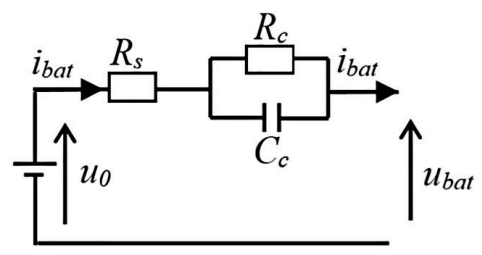

Fig. 2. Battery structural model

$$
\begin{gathered}
i_{b a t}=\frac{u_{0}-R_{s} i_{b a t}-u_{b a t}}{R_{c}}+C_{c} \frac{d}{d t}\left(u_{0}-R_{s} i_{b a t}-u_{b a t}\right) \\
S O C_{b a t}=S O C_{\text {init }}-\frac{100}{360 Q_{b a t}} \int i_{b a t} d t, 0<S O C_{b a t}<1
\end{gathered}
$$

It is worth mentioning that in the current work, cycling aging has been taken into account, and the calendar aging has not been considered.

\section{ENERGY MANAGEMENT STRATEGY}

The EMS in this work is a rule-based control system through which power flow of the FC and battery system is managed such that maximum efficiency is achieved. For this purpose, a fuzzy control system is employed. Figure 3 illustrates the schematic diagram for the fuzzy control system, as it is seen in this figure, the inputs for the controller are the battery SOC and the total power demand from the vehicle, and the output of the EMS is the reference FC current.

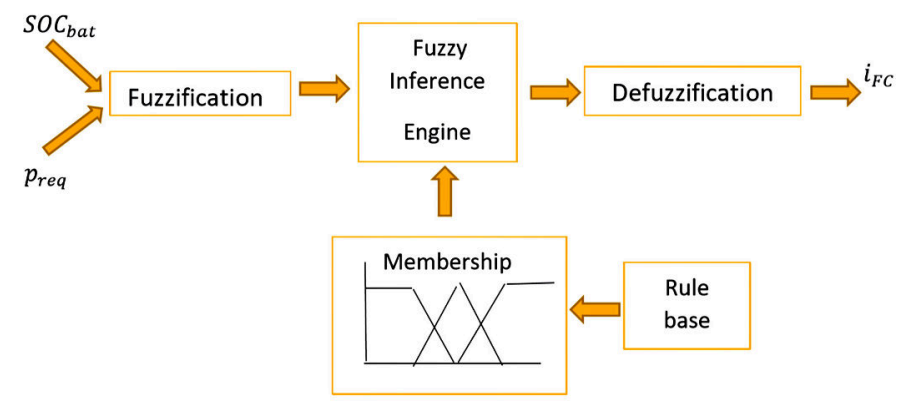

Fig. 3. Fuzzy structure of the energy management

Furthermore, the performance of the EMS is optimized using a genetic algorithm similar to [24]. For this purpose, the EMS system is formulated as an optimization problem in which the parameters of the fuzzy controller are tuned based on an objective function. The objective function in 
the genetic optimization is an aggregated cost function which combines the costs of FC degradation, battery degradation, battery recharge step, and hydrogen consumption.

$$
\$_{\text {global }}=\$_{\triangle f c}+\$_{\Delta b a t}+\$_{\text {charge }}+\$_{H_{2}}
$$

Where $\$_{\text {global }}$ is the global cost, $\$_{\triangle f c}$ is the FC degradation cost, $\$_{\Delta b a t}$ is the battery degradation cost, $\$_{\text {charge }}$ is the cost of battery recharge penalty to reach the full charge level, and $\$_{H_{2}}$ is the fuel consumption cost. The FC degradation is calculated by:

$$
\begin{gathered}
\Delta_{f c}(k)=N_{\text {switch }} \triangle_{\text {switch }}+\int_{0}^{\tau} \delta(k) d k \\
\delta(k)=\frac{\delta_{0}}{3600}\left(1+\frac{\alpha}{P_{f c-n o m}^{2}}\left(P_{f c}(k)_{-} P_{f c-n o m}\right)^{2}\right)
\end{gathered}
$$

where $\mathrm{k}$ is the sampling time, $\Delta_{f c}$ is the $\mathrm{FC}$ degradation, $N_{\text {switch }}$ is the number of start of the FC, $\Delta_{\text {switch }}$ is a start stop degradation coefficient, $\delta_{0}$ and $\alpha$ are load coefficients and $P_{f c-n o m}$ is the nominal power of the $\mathrm{FC}$ in terms of degradation. Cost of the FC system degradation is obtained by:

$$
\$_{\triangle f c}(k)=\Delta_{f c}(k) F C_{c o s t}
$$

where $F C_{\text {cost }}=600$ US $\$$, defined by the US Department of Energy. Cost of $\mathrm{H}_{2}$ consumption for a trip is determined by:

$$
\$_{H_{2}}=H_{2 \operatorname{cost}} \int_{0}^{\tau} \dot{m}_{H_{2}} d k
$$

where $\dot{m}_{H_{2}}$ is hydrogen mass flow and $H_{2 \text { cost }}=3.5 \frac{U S \$}{\mathrm{kgH} 2}$ based on the 2020 projection. Cost of the battery degradation is formulated as:

$$
\$_{\Delta b a t}(k)=\Delta_{b a t}(k) B A T_{\text {cost }}
$$

Where $B A T_{\text {cost }}=640 U S \$\left(\frac{200 U S \$}{k W h}\right), \Delta_{b a t}(k)$ is the battery degradation function, obtained by:

$$
\begin{gathered}
\Delta_{b a t}(k)=\frac{1}{Q_{\text {bat-max }}} \int_{0}^{\tau}\left|F\left(\operatorname{soc}_{\text {bat }}\right) G\left(i_{\text {bat }}\right) i_{\text {bat }(k)}\right| d k \\
F\left(S O C_{\text {bat }}\right)=1+3.25\left(1-S O C_{\text {bat }}\right)^{2} \\
\begin{cases}G\left(i_{\text {bat }}\right)=1+0.45 \frac{i_{\text {bat }}}{\left.i_{\text {bat }}\right) \text { inom }} & \text { if } i_{\text {bat }} \geq 0 \\
G\left(i_{\text {bat }}\right)=1+0.55 \frac{\left|i_{\text {bat }}\right|}{i_{\text {bat }} \text { nom }} & \text { if } i_{\text {bat }}<0\end{cases}
\end{gathered}
$$

Where $Q_{b a t-\max }$ is the entire life battery capacity and $i_{\text {bat-nom }}$ the nominal current related to the battery capacity $Q_{b a t}$.

\section{SIMULATION STUDY AND RESULTS ANALYSIS}

In order to study and compare the impact of the battery aging on the EMS at various battery conditions, three different scenarios have been considered. In the first scenario, called New $w_{\text {Opt }}$, the EMS is optimized for a new battery, which means the battery model and the SOC calculation are based on the parameters of a new battery (specially capacitance and internal resistance). In the second scenario, called $\operatorname{Old}_{O p t}$, the optimization process of EMS is performed by using a degraded battery model. The degradation criteria in this case, according to which the degraded battery model is built, are 20 percent capacity fade and 100 percent increase in the internal resistance. Moreover, the SOC calculation in this scenario is based on the reduced capacitance and increased resistance of the battery owing to degradation. The aim of the mentioned scenarios is to study the influence of the battery $\mathrm{SOH}$, which is the real battery capacity and resistance, on the EMS performance. The third scenario, called $\operatorname{Old}_{N o U p}$, studies the impact of inaccurate SOC feedback on EMS which may occur due to unobserved battery aging. In this scenario, it is assumed that the battery is degraded and the old battery model is employed for the simulations. However, the SOC calculation is made by using the parameters of a new battery to generate false SOC input for the EMS and observe the effect of not updating the SOC calculation on the EMS performance. The utilized EMS in $O l d_{N o U p}$ scenario is the one optimized with a new battery model. Two standard driving patterns including UDDS and WVUINTER driving cycles (Fig. 4) have been considered in the simulations.
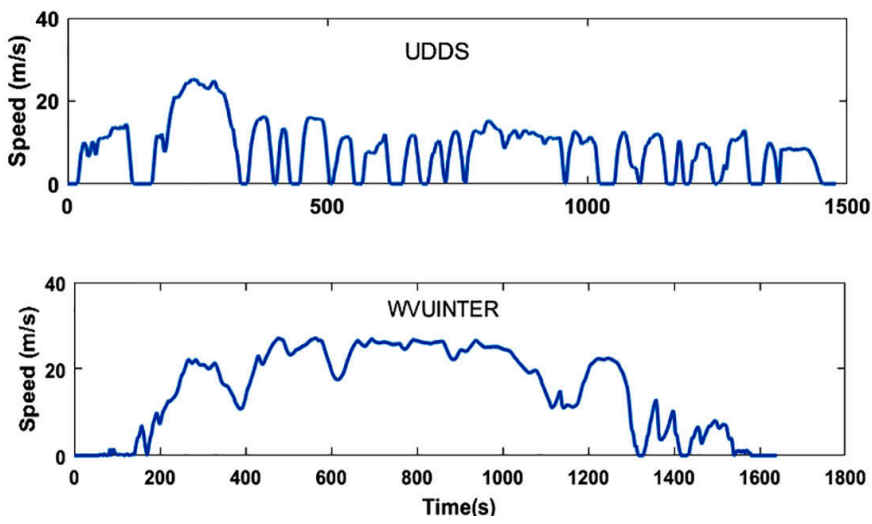

Fig. 4. Driving cycles

Regarding the GA, it is worth mentioning that the number of generation is 50 and the population size is 100. Some limitations have been included while defining the objective function, in the aforementioned formulas. Fig. 5 shows the inputs and output MFs of the FLC before and after tuning with GA under UDDS driving cycle. The optimization trend of the objective function is shown in Fig 6 .

Fig. 7 depicts the demanded power from the FC stack for the aforementioned EMS scenarios. As it is seen in this figure, the drawn power from the FC stack in New 

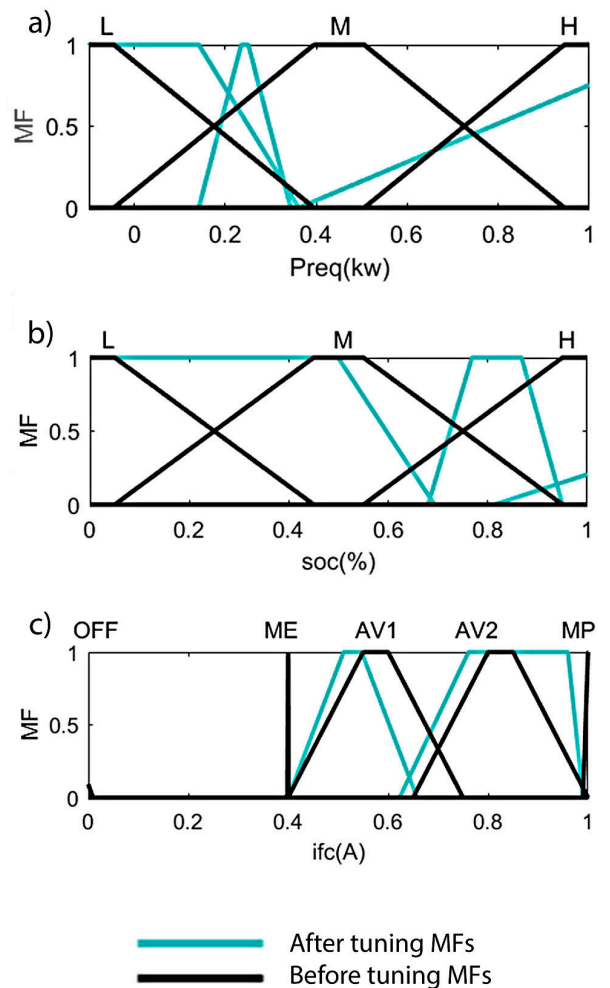

Fig. 5. Fuzzy MFs Before and after tuning process, a) Input 1: requested power, b) Input 2: battery SOC, c) Output 1: demanded current from the FC

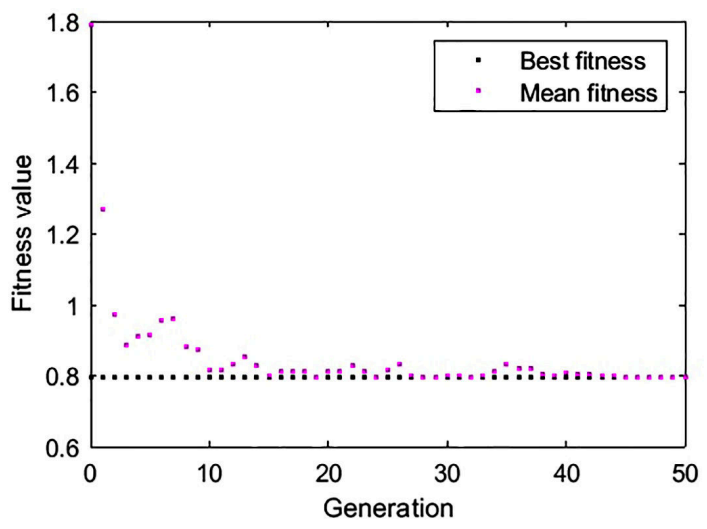

Fig. 6. Optimization trend

$\left(P_{F C} N e w_{O p t}\right)$ is nearly the same as the FC drawn power in Old $d_{N o U p}$ scenario $\left(P_{F C} O l d_{N o U p}\right)$. This is due to the fact that both of these scenarios use the same optimized FLC which results in receiving the same feedback signal for requesting power from the FC stack if in both scenarios the SOC variation stays within a specific zone. However, in the Old $O p t$ scenario where the controller receives the correct SOC feedback, the FC power differs from the other controllers. Let's have a look at the battery SOC in this driving cycle in Fig. 8. According to this figure, the final battery SOC in $O l d_{N o U p}$ scenario is less than the one in New $\mathrm{Opt}$ scenario though they both demanded the same amount of power from the FC. This is actually the effect of false SOC input in the performance of the EMS in $O l d_{N o U p}$ scenario. Regarding the Old $d_{O p t}$ EMS scenario, the SOC drop is recognized in a while and the battery has started to be replenished according to the control command. Fig. 9 shows the FC power for the WVUINTER driving cycle. This driving cycle, in comparison with UDDS, is more power demanding and seems like a good challenge for the EMS to demonstrate its performance during a wider SOC variation. The drawn power from the FC stack has the same interpretation as the one obtained for the UDDS driving cycle until the third quarter of the driving cycle where a considerable difference between the FC power profiles is seen. This difference is due to the controller performance where more rules of FLC have been fired by the controller as a result of the wider SOC variation. As it is seen in figure 10, the battery SOCs for the $O l d_{O p t}$ and New $O p t$ reach nearly the same level at the end of the driving cycle implying the FC endeavors to replenish the battery in these scenarios. However, in $\operatorname{Old}_{N o U p}$ scenario, the final SOC is less than the other two scenarios owing to the false SOC feedback signal.

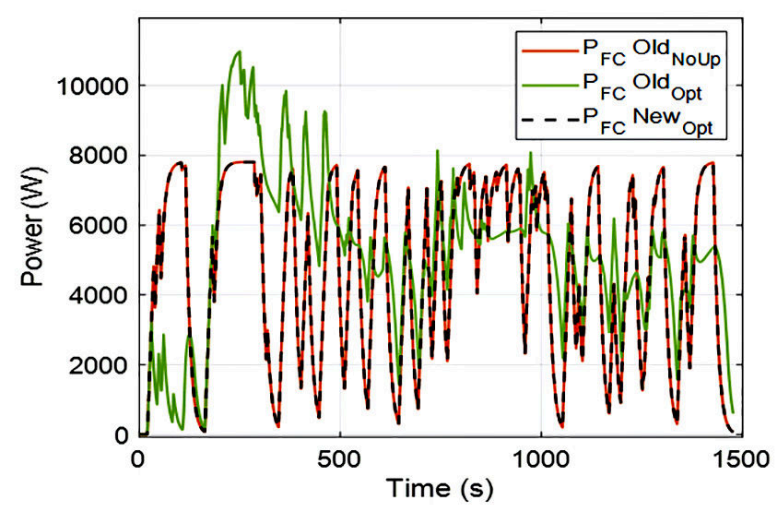

Fig. 7. Power supplied by the fuel cell in UDDS

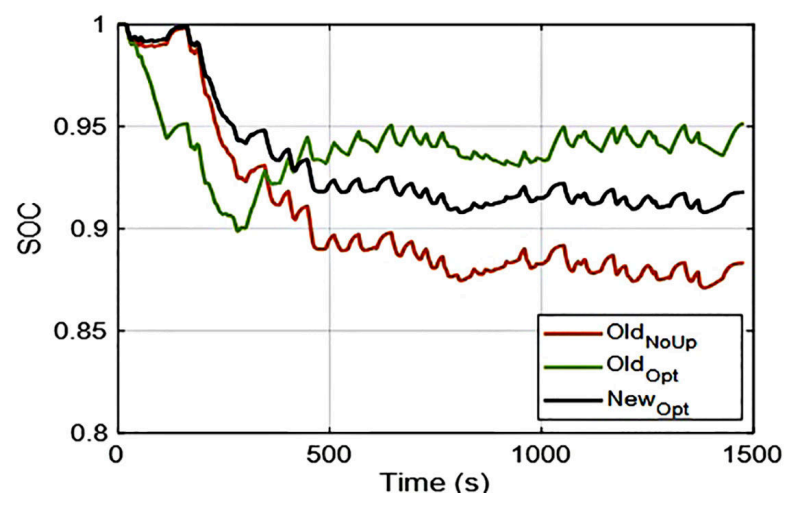

Fig. 8. Battery SOC for different scenarios in UDDS 


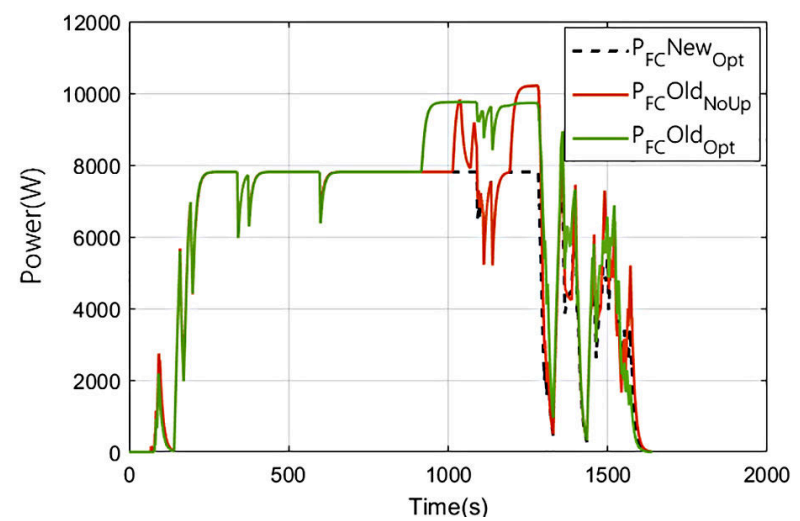

Fig. 9. Power supplied by the fuel cells in WVUINTER

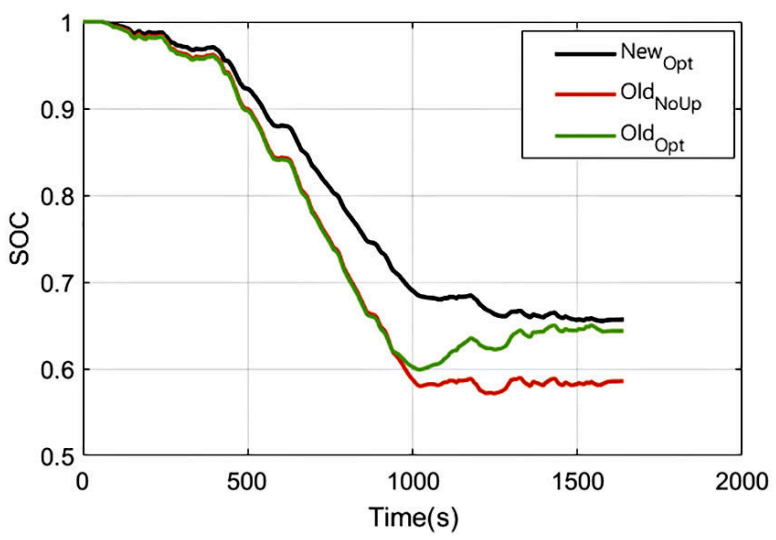

Fig. 10. Battery SOC for different scenarios in WVUINTER

Fig. 11 compares the cost function of various scenarios with respect to the driving cycles. The comparison of $N e w_{O p t}$ and Old $_{O p t}$ scenarios indicate that the degradation of battery has resulted in the increase of cost in both cases. Furthermore, not updating the SOC calculation while the battery gets degraded, which is $O l d_{N o U p}$ scenario, has increased the total cost noticeably. In UDDS driving cycle, the total cost of $O l d_{N o U p}$ scenario is $6.5 \%$ more than $N e w_{O p t}$ and $3.5 \%$ more than Old $_{O p t}$, and regarding the WVUINTER driving cycle, it is $10 \%$ and $2.5 \%$ more than $N e w_{O p t}$ and Old $O p t$ scenarios respectively. It should be noted that the cost functions are higher at WVUINTER driving cycle than their corresponding values at the UDDS driving cycle for all scenarios due to the demanding nature of the WVUINTER driving cycle. These results prove the necessity of an online EMS which takes the battery $\mathrm{SOH}$ into account.

TABLE I also compares the fuel consumptions for the both driving cycles at various scenarios. According to the simulation results, for the $O l d_{N o U p}$ scenario in which the battery is degraded and false input is used for the EMS, the fuel consumption is more than the other scenarios. These results also prove the impact of the battery aging on the fuel consumption even if the controller is optimized for the old battery.

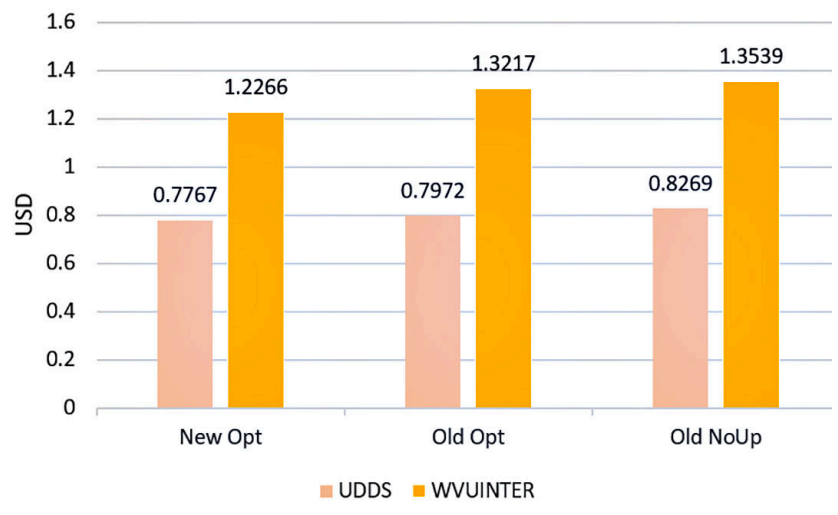

Fig. 11. Global cost comparison

TABLE I

H2 CONSUMPTION

\begin{tabular}{|c|c|c|c|c|}
\hline $\begin{array}{c}\text { Driving } \\
\text { cycle }\end{array}$ & $\begin{array}{c}\text { EMS } \\
\text { case } \\
\text { study }\end{array}$ & $\begin{array}{c}\mathrm{H}_{2} \\
\text { Consumption } \\
(\mathrm{g})\end{array}$ & $\begin{array}{c}\text { Equivalent } \\
\mathrm{H}_{2} \\
\text { Consumption } \\
(\mathrm{g})\end{array}$ & $\begin{array}{c}\text { Total } \mathrm{H}_{2} \\
\text { Consumption } \\
(\mathrm{g})\end{array}$ \\
\hline \multirow{3}{*}{ UDDS } & Old $_{\text {Opt }}$ & 153.23 & 11.17 & 164.4 \\
& New $_{\text {Opt }}$ & 142.40 & 17.64 & 160.04 \\
& Old $_{\text {NoUp }}$ & 142.40 & 27.78 & 170.18 \\
\hline \multirow{3}{*}{ WVUINTER } & Old $_{\text {Opt }}$ & 207.98 & 87.44 & 295.42 \\
& New $_{\text {Opt }}$ & 191.81 & 84.15 & 275.96 \\
& Old $_{\text {NoUp }}$ & 198.93 & 102.21 & 301.14 \\
\hline
\end{tabular}

\section{CONCLUSION}

This paper investigates the impact of battery degradation on the EMS of a FCHEV. In this regard, a fuzzy controller is proposed as the EMS. The parameters of the EMS are then tuned using a genetic algorithm for three scenarios defined for new and old batteries. The cost function in the optimization process includes not only the battery and FC degradation costs, but also the costs of fuel consumption and the battery recharging. Two different driving cycles have been employed to evaluate the performance of the EMSs. Simulation results reveal that the battery aging has a considerable impact on the fuel consumption and total cost of FCHEV. Moreover, tuning the EMS according to the battery $\mathrm{SOH}$ can result in the decrease of the total cost.

\section{REFERENCES}

[1] A. Solouk, M. Shakiba-Herfeh, J. Arora, and M. Shahbakhti, "Fuel consumption assessment of an electrified powertrain with a multimode high-efficiency engine in various levels of hybridization," Energy Conversion and Management, vol. 155, pp. 100-115, 2018/01/01/ 2018.

[2] M. Hamamoto, "An empirical study on the behavior of hybrid-electric vehicle purchasers," Energy Policy, vol. 125, pp. 286-292, 2019/02/01/ 2019.

[3] S. Ahmadi, S. M. T. Bathaee, and A. H. Hosseinpour, "Improving fuel economy and performance of a fuel-cell hybrid electric vehicle (fuelcell, battery, and ultra-capacitor) using optimized energy management strategy," Energy Conversion and Management, vol. 160, pp. 74-84, 2018/03/15/ 2018.

[4] H. Chen, Z. Song, X. Zhao, T. Zhang, P. Pei, and C. Liang, "A review of durability test protocols of the proton exchange membrane fuel cells for vehicle," Applied Energy, vol. 224, pp. 289-299, 2018/08/15/ 2018. 
[5] S. J. Andreasen, L. Ashworth, S. Sahlin, H.-C. Becker Jensen, and S. K. Kær, "Test of hybrid power system for electrical vehicles using a lithium-ion battery pack and a reformed methanol fuel cell range extender," International Journal of Hydrogen Energy, vol. 39, pp. 18561863, 2014/01/22/ 2014.

[6] J. Jaguemont, L. Boulon, and Y. Dubé, "A comprehensive review of lithium-ion batteries used in hybrid and electric vehicles at cold temperatures," Applied Energy, vol. 164, pp. 99-114, 2016/02/15/ 2016.

[7] K. Song, H. Chen, P. Wen, T. Zhang, B. Zhang, and T. Zhang, ”A comprehensive evaluation framework to evaluate energy management strategies of fuel cell electric vehicles," Electrochimica Acta, vol. 292, pp. 960-973, 2018/12/01/ 2018.

[8] P. Kemper, P. Rehlaender, U. Witkowski, and A. Schwung, "Competitive Evaluation of Energy Management Strategies for Hybrid Electric Vehicle Based on Real World Driving," in 2017 European Modelling Symposium (EMS), 2017, pp. 151-156.

[9] H. Li, A. Ravey, A. N. Diaye, and A. Djerdir, "A Review of Energy Management Strategy for Fuel Cell Hybrid Electric Vehicle," in 2017 IEEE Vehicle Power and Propulsion Conference (VPPC), 2017, pp. 1-6.

[10] N. Sulaiman, M. A. Hannan, A. Mohamed, P. J. Ker, E. H. Majlan, and W. R. Wan Daud, "Optimization of energy management system for fuel-cell hybrid electric vehicles: Issues and recommendations," Applied Energy, vol. 228, pp. 2061-2079, 2018/10/15/ 2018.

[11] M. Kandi Dayeni and M. Soleymani, "Intelligent energy management of a fuel cell vehicle based on traffic condition recognition," Clean Technologies and Environmental Policy, vol. 18, pp. 1945-1960, 2016/08/01 2016.

[12] M. Kandi-D, M. Soleymani, and A. A. Ghadimi, "Designing an Optimal Fuzzy Controller for a Fuel Cell Vehicle Considering Driving Patterns," Scientia Iranica, vol. 23, pp. 218-227, 2016.

[13] R. Zhang, J. Tao, and H. Zhou, "Fuzzy Optimal Energy Management for Fuel Cell and Supercapacitor Systems Using Neural Network Based Driving Pattern Recognition," IEEE Transactions on Fuzzy Systems, vol. 27, pp. 45-57, 2019.

[14] J. Chen, C. Xu, C. Wu, and W. Xu, "Adaptive Fuzzy Logic Control of Fuel-Cell-Battery Hybrid Systems for Electric Vehicles," IEEE Transactions on Industrial Informatics, vol. 14, pp. 292-300, 2018.

[15] M. Boukhnifer, N. Ouddah, T. Azib, and A. Chaibet, "Intelligent energy management for hybrid fuel cell/battery system," COMPEL - The international journal for computation and mathematics in electrical and electronic engineering, vol. 35, pp. 1850-1864, 2016.

[16] M. Yue, S. Jemei, R. Gouriveau, and N. Zerhouni, "Review on healthconscious energy management strategies for fuel cell hybrid electric vehicles: Degradation models and strategies," International Journal of Hydrogen Energy, vol. 44, pp. 6844-6861, 2019/03/08/ 2019.

[17] M. Kandidayeni, A. Macias, A. A. Amamou, L. Boulon, and S. Kelouwani, "Comparative Analysis of Two Online Identification Algorithms in a Fuel Cell System," Fuel Cells, vol. 18, pp. 347-358, 2018.

[18] M. Kandidayeni, A. Macias, A. A. Amamou, L. Boulon, S. Kelouwani, and H. Chaoui, "Overview and benchmark analysis of fuel cell parameters estimation for energy management purposes," Journal of Power Sources, vol. 380, pp. 92-104, 2018/03/15/ 2018.

[19] M. Yue, S. Jemei, R. Gouriveau, and N. Zerhouni, "Developing a HealthConscious Energy Management Strategy Based on Prognostics for a Battery/Fuel Cell Hybrid Electric Vehicle," in 2018 IEEE Vehicle Power and Propulsion Conference (VPPC), 2018, pp. 1-6.

[20] Z. Liu, A. Ivanco, and S. Onori, "Aging characterization and modeling of nickel-manganese-cobalt lithium-ion batteries for $48 \mathrm{~V}$ mild hybrid electric vehicle applications," Journal of Energy Storage, vol. 21, pp. 519-527, 2019/02/01/ 2019.

[21] E. V. Thomas, H. L. Case, D. H. Doughty, R. G. Jungst, G. Nagasubramanian, and E. P. Roth, "Accelerated power degradation of Li-ion cells," Journal of Power Sources, vol. 124, pp. 254-260, 2003/10/01/ 2003.

[22] J. Vetter, P. Novák, M. R. Wagner, C. Veit, K. C. Möller, J. O. Besenhard, et al., "Ageing mechanisms in lithium-ion batteries," Journal of Power Sources, vol. 147, pp. 269-281, 2005/09/09/ 2005.

[23] C. Depature, S. Jemei, L. Boulon, A. Bouscayrol, N. Marx, S. Morando, et al., "IEEE VTS Motor Vehicles Challenge 2017 - Energy Management of a Fuel Cell/Battery Vehicle," in 2016 IEEE Vehicle Power and Propulsion Conference (VPPC), 2016, pp. 1-6.

[24] M. K. Dayeni, A. Macias, C. Depature, L. Boulon, S. Kelouwani, and H. Chaoui, "Real-Time Fuzzy Logic Strategy Scheme for Energetic Macroscopic Representation of a Fuel Cell/Battery Vehicle," in 2017 IEEE Vehicle Power and Propulsion Conference (VPPC), 2017, pp. 1-6. 
2020-01-09

\section{Investigation of the battery degradation impact on the energy management of a fuel cell hybrid electric vehicle}

Ghaderi, Razieh

IEEE

Ghaderi R, Kandidayeni M, Soleymani M, Boulon L. (2020) Investigation of the battery degradation impact on the energy management of a fuel cell hybrid electric vehicle. In: 2019 IEEE Vehicle Power and Propulsion Conference (VPPC), 14-17 October 2019, Hanoi, Vietnam https://doi.org/10.1109/VPPC46532.2019.8952303

Downloaded from Cranfield Library Services E-Repository 